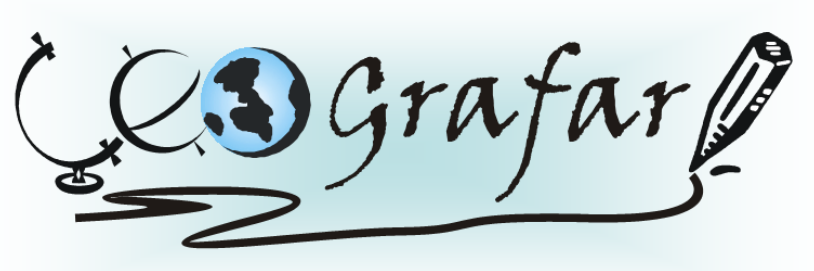

Revista Eletrônica do Programa de Pós-Graduação em Geografia - UFPR

\title{
A VISÃO DO MUNDO VIVIDO RIBEIRINHO NAS OBRAS DE CHARLES WAGLEY
}

\section{THE VISION OF THE WORLD LIVED IN RIVERSIDE WORKS OF CHARLES WAGLEY}

\author{
(Recebido em 25.01.13; Aceito em 03.12.13)
}

\author{
Klondy Lúcia de Oliveira Agra \\ Mestre em Linguística (UNIR), \\ Doutorando em Geografia pela UFPR. \\ Professora da Faculdade Interamericana \\ de Porto Velho (UNIRON), Brasil \\ e-mail: klondy2@gmail.com
}

Adnilson de Almeida Silva Mestre em Geografia (UNIR) e Doutor em Geografia (UFPR). Professor do Departamento de Geografia e do Programa de Mestrado em Geografia e do Programa de Mestrado e Doutorado em Desenvolvimento Regional e Meio Ambiente (UNIR). Pesquisador do GEPCULTURA/UNIR, Brasil e-mail: adnilsonn@gmail.com

\begin{abstract}
RESUMO
Os espaços de vivências ribeirinhas na Amazônia tem sido tema de pesquisas diversas. Neste artigo, através de pesquisa bibliográfica, analisamos como a pesquisa tem tratado esse tema. Com o objetivo principal de conhecer o homem e a mulher amazônicos, ou seja, conhecer e compreender como é representada a (s) identidade (s) cultural (ais) do povo ribeirinho da Amazônia sob olhares diversos. O presente artigo apresenta a visão do mundo vivido ribeirinho presente nas obras do antropólogo Charles Walter Wagley, um dos primeiros cientistas americanos a trabalhar nas chamadas "terras baixas" da América do Sul no Brasil, notadamente na Amazônia, tendo influenciado vários pensadores brasileiros como é o caso do antropólogo Eduardo Enéas Gustavo Galvão. Wagley deu importante contribuição à ciência por meio de várias obras, sendo que "Uma comunidade amazônica, um estudo do homem nos trópicos" é considerada como a mais importante e se tornou
\end{abstract}


uma referência clássica não somente para a Antropologia, mas também para outras áreas do conhecimento relacionadas à sociedade e à humanidade. É importante destacar que a visão de mundo pelo olhar do outro em vários momentos da história humana é tido como "enviesado", o que carrega consigo a ideia de colonialismo nesse caso acadêmico - sobre homens e mulheres que compartilham signos, significados, representações, experiências, vivências e modos de vida que se confrontam e consubstanciam-se como "encontro de sociedades", conforme descrito por Eduardo Galvão. O entender o homem e a mulher amazônicos em suas múltiplas representações (ribeirinhos, caboclos, beiradeiros, indígenas, extrativistas, entre outros) passam pela lógica de que a compreensão de suas temporalidades e territorialidades possui códigos distintos de apropriação, cujo sentido consiste na interpretação e vivências com o meio onde estabelecem relações sociais, míticoreligiosas e culturais.

Palavras Chaves: Amazônia, Cultura, Ribeirinhos.

\begin{abstract}
The spaces of riverine experiences in the Amazon has been the subject of several studies. In this article, through bibliographical research, analyze how the research has dealt with this theme. With the main objective to meet the man and the Amazonian woman, i.e., know and understand how is represented (s) (s) cultural identity (ais) of the people of the Amazon Riverside under various looks. This article presents the vision of the world lived in Riverside works of anthropologist Charles Walter Wagley, one of the first American scientists to work in so-called "lowlands" in South America in Brazil, notably in the Amazon, having influenced several Brazilian thinkers such as anthropologist Eduardo Gustavo Enéas Galvão. Wagley gave important contribution to science by means of various works, being that "a community, a study of the Amazonian man in the tropics" is regarded as the most important and has become a classic reference not only to the anthropology, but also to other areas of knowledge related to society and humanity. It is important to highlight that the worldview by looking at the other at various times of human history is regarded as "skewed", which carries with it the idea of colonialism - in this case academic - that men and women can share signs, meanings, representations, experiences, experiences and ways of life that are faced and underpin "meeting of societies", as described by Eduardo Galvão. The man and woman understand Amazon in its multiple representations (bordering, caboclos, beiradeiros, indigenous peoples, extractivists, among others) pass by the logic that the understanding of their temporalities and territorialities have distinct codes of appropriation, which consists in interpreting and experiences with the middle where social relations, mythical-religious and cultural.
\end{abstract}

Keywords: Amazon, Culture, River man. 


\section{INTRODUÇÃO}

A literatura sobre a região amazônica apresenta resultados de distintas perspectivas sobre essa rica e diversa área do planeta. Uma riqueza expressa, não só pela sua reserva biogenética, mas também pela sua diversidade sociocultural. Com grande número de povos, com diferentes linguagens e representações de mundos, constitui-se em enorme etnodiversidade, razão pela qual desperta 0 interesse de diferentes pesquisadores com objetivos diversos. Tal etnodiversidade é constituída de indígenas, caboclos, ribeirinhos e negros remanescentes com seus conhecimentos e riquezas culturais peculiares.

Neste estudo, o objetivo principal é o de conhecer o homem e a mulher amazônicos, ou seja, conhecer e compreender como é representada a (s) identidade (s) cultural (ais) do (s) povo (s) ribeirinho (s) da Amazônia sob olhares diversos. Considera-se que processos de conhecer, saber, viver e fazer dentro dessa imensa fronteira são preponderantes à adaptação e assimilação do homem a essa região.

Compreende-se também que ribeirinho refere-se àquele ser humano que anda pelos rios e que tem no rio a base de sua sobrevivência. Um homem que sonha, vive e crê, tem o rio e a mata como seu espaço, seu lugar, seu mundo vivido. Os primeiros estudos sobre ribeirinhos amazônicos apareceram nos anos cinquenta, com os trabalhos pioneiros de Galvão (Panema: uma crença do caboclo amazônico, 1951), Wagley (Race and Class in Rural Brazil, 1952) e Sternberg (A água e o homem na Várzea do Cordeiro, 1956) (HARRIS, 2006). Nesses e em outros trabalhos sobre ribeirinhos da Amazônia, os autores descrevem suas comunidades como compostas em sua grande maioria por moradores que dividem o tempo entre a agricultura e a pesca (FURTADO, 1993).

A fim de conhecer o homem ribeirinho amazônico através de literaturas diversas, neste estudo, fazemos uma releitura dos estudos culturais iniciais que procuravam conhecer e descrever essas comunidades. Esses elementos culturais qualificam o espaço heterogeneamente como um fenômeno fundamental da vivência de qualquer agrupamento humano (CASSSIRER, 1968, p. 194 [1944]).

Tais questões são corroboradas pelas exterioridades socioculturais do homem e da mulher amazônicos sobre as formas do sentir, do pensar e do ser humano, cujos atributos e implicações ocorrem como representação territorial e 
social. Assim é possível refletir sobre essa complexidade humana em seu processo de construção de sua identidade cultural e a relação com o meio socioespacial que se apresentam de formas distintas da cultura urbana ${ }^{1}$.

Um caminho possível para se alcançar o entendimento sobre essa população pode ser marcada pelas representações e formas simbólicas com as quais se depara em seu cotidiano, com valores que são compreendidos e apreendidos por suas vivências e experiências no lugar, sendo de interesse da Geografia Cultural e Humanística.

Apesar de abordar diretamente sobre o ser ribeirinho, Nugent (2006, p.35) inicia seu ponto de vista sobre as sociedades amazônicas avaliando que as mesmas possuem raízes tanto não indígenas quanto indígenas, de modo que solidifica uma identidade própria e híbrida, como resultante da herança recebida pelos diversos processos de ocupação que ocorreram e ocorrem no espaço amazônico.

Em sua avaliação, este autor argumenta que a condição econômica e social das sociedades amazônicas dentro do contexto das macroestruturas e macroconjunturas do país e da própria região possibilidade uma relação assimétrica em decorrência de que no imaginário coletivo o conceito da produção dos amazônidas (ribeirinhos, caboclos, indígenas, entre outros) só tenha utilidade como meio de subsistência, com isso encontram-se alijado do projeto desenvolvimentista, portanto, por se adaptarem ao sistema econômico constituem-se como entrave ao avanço das relações que se realizam no espaço.

Desta forma, nosso trabalho buscou estabelecer uma análise com aporte de outras áreas do conhecimento, no entanto, retomamos a chamada virada linguística na Geografia e sua importância para os estudos voltados a essas comunidades e procuramos por estudos recentes que envolvem a percepção na geografia, representações e mapas mentais utilizados na revelação dessas identidades amazônicas.

\footnotetext{
${ }^{1}$ O pensar cultural-urbano em muitas partes da Amazônia possui outras dimensões interpretativas que se distinguem dos centros urbanos consolidados no país e no mundo, em decorrência da relação que seus habitantes estabelecem com os rios, onde esses se constituem como integrante do modo de vida. Não tem como desassociá-los desse processo, visto que o rio é a estrada, é o acesso às exterioridades, conforme observam Trindade Júnior e Tavares (2008).
} 


\section{OS PRIMEIROS OLHARES SOBRE O RIBEIRINHO AMAZÔNICO}

O marco fundador no estudo antropológico das sociedades ribeirinhas da Amazônia, para a maior parte dos acadêmicos contemporâneos, está nos trabalhos de Charles Wagley e Eduardo Galvão². Esses estudos culturalistas tiveram origem norte americana, descendentes do particularismo histórico boasiano ${ }^{3}$ e da origem cultural de Julian Steward.

A pesquisa brasileira de Charles Wagley começou em 1939-40 na floresta dos Tapirapé. Seu artigo publicado em 1940 The Effects of Depopulation upon Social Organization, as Illustrated by Tapirapé Indians é um clássico da antropologia demográfica. Da revisita de Wagley aos Tapirapé culminou o seu último livro Welcome of Tears: The Tapirapé Indians of Central Brazil (1977). A pesquisa de Wagley entre os Tenetehara em 1941-42, com seu amigo e colaborador frequente Eduardo Galvão ${ }^{4}$, resultou também em livro: The Tenetehara Indians of Brazil, editado em 1949.

Seu estudo sobre o homem amazônico registra as memórias do dia a dia de trabalhadores rurais e seringueiros da Amazônia. Estudos que começaram em 1948 e produziram duas edições dessa obra que é a mais popular do autor: Amazon Town: a Study of Man in the Tropics $(1953,1976)$. Ainda sobre a Amazônia, Wagley editou em 1974, Man in the Amazon. Esses livros e vários artigos de seus diários, em inglês e em português, deram ao autor enorme reputação como pioneiro dos estudos amazônicos.

Amazon Town, escrito por Charles Wagley, foi baseado, principalmente, em dados coletados pelo autor em seus primeiros estudos sobre o homem na Amazônia brasileira. Dados coletados em 1948, quando a serviço da UNESCO, através da Organização Cultural, Científica e Educacional das Nações Unidas, pesquisa a Amazônia para o Instituto Internacional da Hiléa Amazônica. Entretanto, a primeira visita do autor ao seu objeto de pesquisa (Itá ${ }^{5}$ ) aconteceu em 1942, durante viagem

\footnotetext{
${ }^{2}$ Produções intelectuais locais representadas por nomes como José Veríssimo e Dalcídio Jurandir, entre outros, muito influenciaram os estudos do homem amazônico.

${ }^{3}$ Charles Wagley foi aluno de Franz Boas.

${ }^{4}$ O brasileiro Eduardo Galvão foi o primeiro aluno doutoral de Wagley.

${ }^{5}$ Nome fictício adotado por Wagley para a pequena comunidade pesquisada.
} 
de estudos que antecedeu o planejamento do Serviço de Saúde Pública (SESP) no Vale Amazônico, visita que lhe despertou, pela primeira vez, a necessidade de um estudo a respeito do homem amazônico.

Durante essa viagem, feita de lancha, descendo o rio Amazonas, em companhia de seu assistente, Cleo Braga, que Wagley ao vivenciar fatos, encontros e conversas com o povo amazônico, sentiu a necessidade de conhecer o homem amazônico. Sobre isso, Charles Wagley declara:

Foi nessa lenta viagem de lancha, descendo o rio Amazonas, na companhia de meu jovem assistente brasileiro e companheiro, Cleo Braga, que, pela primeira vez, tive consciência da cultura amazônica e da necessidade de um estudo da vida do homem da Amazônia. À medida que visitávamos as aldeias e os postos de comércio do Baixo Amazonas e que conversávamos com pessoas de todas as classes sociais, cheguei à conclusão que a exótica magnificência do panorama tropical havia desviado as atenções do homem do Vale Amazônico. ${ }^{6}$ [Nossa tradução].

Nessa primeira visita de Wagley ao cenário que utilizaria como fonte de pesquisa, o autor reconhece a pouca importância dada pela literatura mundial à cultura e ao homem amazônico e declara ainda no prefácio de Amazon Town: "As clássicas narrações de H.W.Bates, Alfred R. Wallace, do tenente William Herndon, de Louis Agassis e outros, que descrevem o grande vale, fazem referências surpreendentemente escassas ao homem e às questões humanas." 7 [Nossa tradução]

Originados e influenciados pela ecologia cultural stewardiana e o culturalismo boasiano de Charles Wagley, vários pesquisadores brasileiros e estrangeiros dedicaram-se a estudar as sociedades amazônicas. Entre esses pesquisadores, podemos citar: Emilio Moran, Eugene Parker, Richarde Pace, Angélica Mota-Maués e Heraldo Maués. No entanto, esses trabalhos descreviam as sociedades, mas ainda não procuravam pela compreensão do homem.

De uma maneira geral, para os antropólogos americanos deste primeiro período os ribeirinhos se expressavam na vida isolada em unidades familiares, com

\footnotetext{
6“It was on this slow trip by launch down the Amazon River, with my young Brazilian assistant and companion Cleo Braga, that first became aware of the richness of Amazon culture and of need for a study of a life of man in the Amazon. As we visited the towns and trading posts of lower Amazon River and we talked with people of all classes, I came to realize that exotic grandeur of the tropical scene had drawn attention away from the activities of man in the Amazon Valley". (In: Wagley, 1976: xvi)

7"The classical accounts of H.W. Bates, of Alfred R. Wallace, of Lieutenant William Herndon, Of Louis Agassiz, and others who describe the great valley have devoted astonishingly little attention to man and the human affairs".(In: Wagley, 1976: xvi)
} 
uma pequena agricultura familiar combinada com a caça e a pesca. Sendo notáveis nesses resultados que mesmo com o envolvimento cultural de pesquisadores com a comunidade pesquisada, as percepções desses estudiosos sobre esse espaços continuavam compostos de representações compartilhadas em sua própria comunidade, uma comunidade estrangeira à Amazônia, que não compreende as pessoas e nem seu modo de vida. Isso fica claro quando observamos a declaração de Charles Wagley, logo nas primeiras linhas de Amazon Town:

Este livro é estudo de uma região e do estilo de vida de seu povo. A região é a Amazônia brasileira onde o estilo de vida distintamente tropical foi formado pela fusão das culturas indígena americana e portuguesa durante os últimos três séculos. Num sentido maior, o livro é estudo da adaptação do homem no ambiente tropical. E, é também, o estudo de caso de uma área "retrógrada" e subdesenvolvida ${ }^{8}$. [Nossa tradução].

Observa-se que, apesar de o autor julgar-se apto a descrever a cultura amazônica, ao olhar a região brasileira como retrógrada e subdesenvolvida, Wagley emite juízo de valor formado através de sentidos construídos em sua cultura de origem (percepções e representações) e que, em seu estudo sobre costumes e modos de vida amazônicos, tais sentidos podem ter interferido.

Assim como Wagley, resultados de outros pesquisadores desse primeiro período trazem o mesmo resultado: vêem o homem amazônico como atrasado e subdesenvolvido e enxergam a cultura do ribeirinho como inferior, por ser estrangeira a eles, uma cultura pronta a ser modificada pelo colonizador (aquele que explora e retira da terra tudo o que lhe convém). Essa visão ainda que errônea, para os dias atuais reflete, para esses autores a exclusividade do pensamento da época, e que implica no não conhecimento sobre o homem amazônico.

Pertencentes a outras culturas, veem a cultura local e o dono da terra, mas não o compreendem. Leem o contexto e o cenário: o indígena, o caboclo e a mistura de raças que originou a comunidade pesquisada e sua cultura, mas ainda não os interpretam, não conseguem compreender porque, apesar de todo o envolvimento, não procuraram por sentidos e significados na cultura amazônica. Uma compreensão errônea que repete a visão das famosas literaturas de viagem a nossa disposição desde os primeiros relatos do Frei Gaspar de Carvajal.

\footnotetext{
8 "This book is a study of a region and the way of life of its people. The region is the Brazilian Amazon where a distinctive tropical way of life has been formed by the fusion of American Indian and Portuguese cultures during the last three centuries. In larger sense, the book is a study of adaptation of man to a tropical environment. It is also a case study of a "backward" and underdeveloped area". (In Wagley, 1976: 2)
} 
Entretanto, novas abordagens nas ciências permitiram um novo olhar sobre o homem e a mulher amazônicos, com a Nova Geografia Cultural exercendo papel destacado na compreensão dos distintos modos de vida como inclusivo, isto é, visto a partir da concepção êmica, ou seja, através da concepção de conceitos e valores que essas populações constroem, vivenciam e experenciam seu mundo - aqui entendido com representação da visibilidade, em razão das mesmas se presentificarem enquanto inseridas no contexto regional e nacional.

\section{A VIRADA LINGUÍSTICA NA GEOGRAFIA E OS ESTUDOS DE RIBEIRINHOS AMAZÔNICOS}

A partir dos anos 1960, houve aumento no número de trabalhos referentes aos ribeirinhos amazônicos. Tais estudos procuravam, em sua grande maioria, analisar os efeitos dos grandes projetos sobre essas comunidades ribeirinhas (MORAN, 1974). Coincidentemente com esse aumento do interesse pelas comunidades da Amazônia, as ciências mundiais urgiam por mudanças e rupturas rumo a novas leituras do mundo.

$\mathrm{Na}$ Geografia (física e humana) surgiram também as primeiras inquietações e propostas de mudança. Segundo Soja (1993, p. 20) tais inquietações "mal se fizeram ouvir no alarido temporal vigente", fazendo com que os debates mais profundos fossem adiados. Foram necessárias quase duas décadas para que o fenômeno pós-moderno ganhasse corpo e força com pensadores de dentro e fora da geografia com nomes como Foucault, Lefebvre, Berger e Mandel considerados por Soja (1993, p.78), fundadores do pós-modernismo.

Numa tentativa de encontrar caminhos para a explicação das diferentes formas que se construíram concomitantemente ao pós-moderno, se coloca na Geografia a necessidade de um estudo que dê conta da explicação das inúmeras linguagens surgidas no contexto vigente. Um caminho que busca a explicação das linguagens do mundo pós-moderno, juntamente com a cultura daqueles que a utilizam. A Geografia começa a reconhecer a necessidade de conhecer os homens e mulheres tal como são no mundo, com suas desigualdades, para só então, poder realizar uma narrativa do espaço, caso contrário essa dimensão é incompleta e 
adquire o caráter simplificado de uma fábula (BERGER, 1984 apud SOJA, 1993, p.31).

A rápida evolução científica, juntamente com as críticas ao pensamento positivista, contribuiu significativamente para o avanço epistemológico das ciências, em especial a geografia. Os geógrafos percebem que "os homens, os grupos e os lugares são realidades variáveis" e que, portanto, merecem ser estudados com maior rigor e profundidade, respeitando sua natureza "material, histórica e geográfica" (CLAVAL, 1999, p.63).

Entram em cena os significados dos signos surgidos meio aos novos parâmetros mundiais que emergiam fortificados pelo poder das mídias, modificando culturas e identidades; criando e recriando maneiras de ver o mundo. Os signos e seus significados se constituem na palavra-chave dessa nova teoria. A imaginação dá significado ao mundo humano, permitindo que o homem a transforme e crie significados para suas ações, através da linguagem. Entretanto, os argumentos e propostas da abordagem Humanista não conseguiram se sustentar por muito tempo. Pautada demasiadamente no corpo humano, nos sentidos e suas relações com o mundo exterior, esquece-se de verificar as coletividades e seu agir diferenciado. Por este e outros motivos, os rumos propostos por esta abordagem acabaram sendo aos poucos abandonados.

No início dos anos 1990, há uma retomada desses estudos onde as linguagens se fazem presentes (COSGROVE, 1998). Essa retomada se faz com um enfoque que requer a contextualização dos signos que se apresentam ao estudo do geográfico. O mundo assistiu nos anos 1990, a um turbilhão de imagens carregadas de significados inseridos nos parâmetros tecnológicos que se faziam presentes. Abrem-se então, novos horizontes, novas possibilidades para a geografia que encontra, por sua vez, na linguagem um arcabouço teórico-metodológico para estudá-la (SAHR, 2005).

A partir daí, o estudo do homem ribeirinho amazônico passa a interessar como o sujeito das mudanças, o construtor de significados que passa através de sua inteiração social a modificar sua própria realidade, construindo e reconstruindo espaços. O estudo dessas comunidades ribeirinhas passa, também, a levar em conta as diferenciações na organização social nessas diversas comunidades amazônicas e as fortes imbricações com o lugar e com a paisagem às quais cada 
uma dessas populações está diretamente relacionada. Desse modo, pesquisadores e estudiosos da Amazônia começaram a reconhecer que as organizações sociais das comunidades ribeirinhas diferem uma da outra e que essa pluralidade de formas está ligada ao modo de vida e nunca a determinação ambiental ou natural, não sendo possível um estudo generalizado desses ribeirinhos.

Com esse reconhecimento, a pesquisa quer mais, ela volta-se à percepção desse homem amazônico. Através da percepção na geográfica, o pesquisador procura pelos conhecimentos e saberes ribeirinhos, procurando, também, pelas representações simbólicas e sociais a fim de saber quem é esse homem amazônico, que vive, sonha e crê na ribeira dos rios.

Nesta perspectiva, essas populações são também denominadas regionalmente como tradicionais, cujo significado para Almeida Silva (2010, p.42), trata-se do

[...] modo de vida ou experiências socioespaciais marcado pela lógica de relações estreitas com 0 meio. Assim, constitui-se como uma visão e interpretação do mundo, cujos valores de formas, representação simbólica e presentificação são distintas daqueles da sociedade envolvente, porque se fundamenta no contexto da sobrevivência material e espiritual na espacialidade e/ou territorialidade e encontra-se desvinculada da ideia de apropriação dos recursos com finalidade econômica [...].

Essa leitura possibilita compreender as relações que essas populações mantêm com o meio em que vivem ao tempo em que constroem sua visão particular de mundo mediada pelas mais distintas representações, cujos atributos e significados são dotados de qualidades próprias que se distinguem em relação às demais coletividades humanas, em virtude de suas apreensões, utilizações e referências simbólicas.

Assim, se tem que mesmo trabalhos importantes, como obras clássicas e dignas de análise a discussão em relação às pesquisas e ensinamentos como as obras de Charles Wagley, merecem questionamentos. Esses questionamentos não invalidam o pensamento do autor, mas nos qualificam a refletir sobre o papel que a sociedade e a ciência fazem e constroem sobre homens e mulheres da Amazônia com seus modos de vida, valores, culturas, relações sociais e ambientais que são postas em confronto com o modelo econômico vigente.

Este é um grande desafio, sobretudo, das últimas décadas com a implantação de projetos de infraestrutura em toda a região que deslocam não apenas as populações, mas que tenta homogeneizar e caracterizar a fronteira econômica, de 
modo a procurar desenvolver mecanismos que apaguem ou invisibilizem homens e mulheres que possuem temporalidades, espacialidades, representações distintas da sociedade urbana.

Para compreender essa questão, a Nova Geografia Cultural em suas abordagens considera a percepção e a representação como o lócus ideal de análise, onde o lugar é a relação íntima do ser humano com o seu meio, pois ali constrói seus valores de identidade cultural e encontra o abrigo necessário para se representar no mundo e perante o mundo, criando os laços indispensáveis à própria existência.

\section{ESTUDOS DA PERCEPÇÃO E DA REPRESENTAÇÃO NA GEOGRAFIA: UM OLHAR CUIDADOSO SOBRE O RIBEIRINHO}

Com a retomada linguística na Geografia, os estudos das populações ribeirinhas voltaram-se para a percepção do homem e para o fato de que as pessoas criam laços afetivos com os lugares onde moram. Passam a reconhecer que o homem ribeirinho identifica-se com o meio, dá forma e constrói sentido na sua cultura, dá significado as coisas, denomina e modifica. O geógrafo passa a compreender a cultura como "a soma dos comportamentos, dos saberes, das técnicas, dos conhecimentos e dos valores acumulados pelos indivíduos durante as suas vidas [...]" (CLAVAL, 2007, p.63) e interessa à pesquisa compreender esse homem para conhecer a sua cultura.

Os estudos em busca da percepção buscam conhecer a maneira pela qual os ribeirinhos respondem ao seu ambiente físico, ou seja, a percepção que dele tem e o valor que nele depositam. Nesses estudos, é levado em conta que a principal diferença entre o processo mental humano e animal é que o homem tem uma capacidade altamente desenvolvida para o comportamento simbólico. "Um símbolo é um repositório de significados. Os significados emergem das experiências mais profundas que se acumulam através do tempo" (TUAN, 1980, p.166), isto é, com qualidades de realizar-se e representar-se perante o mundo através de seu espaço de ação (CASSIRER, 1968, p.71 [1944]).

Estas experiências acumuladas são formadas por uma longa sucessão de percepções que dão origem às atitudes que orientam ações para com o meio 
ambiente circundante. Logo, a relação para com o meio ambiente tem influência direta dos sentimentos e valores que são depositados nestes. A percepção é tanto a resposta dos sentidos aos estímulos externos, como a atividade proposital na qual certos fenômenos são claramente registrados, enquanto outros retrocedem para a sombra ou são bloqueados. Muito do que percebemos tem valor para nós, para a sobrevivência biológica, e para propiciar algumas satisfações que estão enraizadas na cultura (TUAN, 1980, p.05).

A percepção configura-se como fator de grande importância na análise em trabalhos que se ocupam do ribeirinho amazônico, proporcionando uma melhor compreensão das relações desses com seus espaços.

Esse método de investigação, a partir da consciência e da percepção das pessoas acerca do mundo que os rodeia permite compreender a essência de muitos fenômenos sociais. Conhecer o mundo vivido ${ }^{9}$ passa a exigir o conhecimento de percepções. Tais estudos trouxeram caminhos a muitos geógrafos que, na tentativa de solucionar problemas epistemológicos, buscaram alternativas na fenomenologia (Eric Dardel, Yi-Fu Tuan, Paul Claval e outros) e propuseram a Geografia Cultural.

Dá-se uma abertura a novos horizontes para a análise da dimensão geográfica da cultura do ribeirinho amazônico com a revalorização do homem que é recolocado no centro das preocupações dos geógrafos culturais, como protagonista de seu próprio mundo.

Nesse sentido, a dimensão cultural surge nas obras de Wagley como uma descrição antropológica sem, no entanto, possuir um aprofundamento que considere as percepções que o homem e a mulher amazônicos como dotados de espiritualidade e originalidade em seus modos de vida e como tratam e representam no meio que estão inseridos.

Assim, as dificuldades causadas pela dimensão geográfica e a relação do ser humano amazônico tradicional com a natureza não podem ser entendidas como algo rústico, displicência, malemolência, preguiça ou como leseira (SOUZA, 2009), isso porque as coisas em si para essa população não são dotadas de valores materiais. É preciso entender que as próprias características geográficas (temperatura, umidade, etc.) são fatores que limitam a ação humana no desenvolver das

\footnotetext{
${ }^{9}$ Essa ideia de mundo vivido é uma ideia que ganhou força a partir de Husserl e foi muito discutida por vários filósofos, como Jean Paul Sartre, Merleau-Ponty e Martin Heidegger, entre outros.
} 
atividades, ademais, com as distâncias enormes e dificuldades de transporte não se justificam a produção em escala comercial e/ou industrial.

É necessário desmitificar e reconhecer que essa população tem outro tipo de conhecimento que é construído pelas relações com os rios, com as florestas, com suas percepções de mundo. Assim, ela conhece seu próprio calendário, ou seja, sabe o período de plantar, de colher, quando terá boa produtividade, quando realizar a estocagem e armazenamento de alimentos, quando pode caçar e pescar, quais as espécies que pode capturar. Nesse sentido, estabelecem acordos com aquilo que a natureza pode propiciar e instituem condições próprias que lhes assegura a sobrevivência física e espiritual.

\section{MAPAS MENTAIS NA CONDUÇÃO DOS SABERES RIBEIRINHOS}

Como um sujeito atuante na sociedade, o ribeirinho vive em intenso contato com o meio do qual participa. Essa percepção do meio não se dá apenas através da captação dos estímulos externos representados pela subjetividade; se dá também por fatores concretos como a percepção do meio através dos sentidos do seu corpo.

[...] por mais diversas que sejam as nossas percepções do meio ambiente, como membros da mesma espécie, estamos limitados a ver as coisas de uma certa maneira. Todos os seres humanos compartilham percepções comuns, um mundo comum, em virtude de possuírem órgãos similares. A unicidade da perspectiva humana tornar-se-á evidente quando pararmos para indagar como a realidade humana deve diferir da dos outros animais (TUAN, 1980, p.6).

A partir de então, em busca das percepções do ribeirinho, a pesquisa geográfica passa a enfatizar as representações como construções imagéticas decorrentes da apreensão dos significados e subjetividades espaciais. Refletindo, desse modo, a percepção e compreensão sociocultural dos indivíduos, que as produzem perpassadas por diferentes prismas em direção ao representativo / simbólico que se situa na base da relação sujeito/signo/imagem (KOZEL, 2009).

O mundo cultural ribeirinho passa a ser considerado por esse ângulo e também a ser compreendido não apenas como uma soma de objetos, mas como uma forma de linguagem explicitada no sistema de relações sociais no qual estão inseridos valores, atitudes e vivências, e essas imagens passam a ser entendidas como mapas mentais. 
A linguagem aparece como uma semantização que os sujeitos fazem de seu espaço vivido ou uma modalidade privilegiada de representação. Essa linguagem é referendada por signos que são construções sociais. É nessa perspectiva que entendemos os mapas mentais: uma forma de linguagem que reflete o espaço vivido representado em todas as suas nuances, cujos signos são construções sociais. (KOZEL, 2007)

Mapas mentais, nesses estudos do ribeirinho amazônico, são compreendidos como uma forma de linguagem que retrata o espaço vivido representado em todas as suas nuances, cujos signos são construções sociais que podem ser construídos por intermédio de imagens, sons, formas, odores, sabores, porém seu caráter significativo prescinde de uma forma de linguagem para ser comunicado. Penetrar nessa intrincada rede de relações pressupõe construção e ação de uma consciência e isso requer diferentes linguagens (KOZEL, 2009).

Os geógrafos estudiosos do espaço ribeirinho têm utilizado os mapas mentais na obtenção das representações do vivido, pois são através das interpretações desses mapas que se reconhecem as trocas que o ribeirinho faz ao longo de sua história com os lugares experienciados por eles. Com a interpretação do mapa mental, obtém-se a representação do saber percebido e o lugar se apresenta tal como ele é, com sua forma e histórias concretas.

Segundo Kozel (2009, p. 04), essa abordagem pode contribuir para que as dicotomias entre homem e signo possam ser rompidas, permitindo refletir além das estruturas formais dos códigos sacralizados em modelos que tudo preveem e definem, na relação entre significado e significante, abrindo uma possibilidade inovadora de perceber o signo como construção dialógica e social, propiciando ver o significante como algo aberto, constantemente criado e recriado pelas ações e interações humanas.

Essas percepções não aparecem nas obras de Wagley e pode ser compreensível, visto que no período em que o autor desenvolve trabalhos na Amazônia, esse espaço geográfico era tido como um vazio, espaço ainda romantizado e exótico, pronto para ser explorado. Mas, há que se destacar que Wagley, ainda que aqui se conteste o seu trabalho, trouxe para a ciência a preocupação de compreender as relações do ser humano amazônico e apresentava suas preocupações quanto às mudanças que ocorriam naquele período. Provavelmente estaria estarrecido, se fosse analisar os dias atuais frente ao quadro que ocorre na região em razão dos deslocamentos forçados, impactos ambientais e 
sociais, entre outros, pela ação de grandes projetos de infraestrutura como é o caso de Belo Monte.

\section{CONSIDERAÇÕES}

Observa-se, portanto, com este estudo, que a pesquisa sobre as populações ribeirinhas amazônicas têm sofrido ao longo do tempo mudanças metodológicas que acompanham as mudanças nos estudos Geográficos. A Geografia, que antes se preocupava com a descrição da terra, com a retomada linguística e as diversas possibilidades oferecidas pela Geografia Cultural, tem se voltado para o estudo do homem como principal sujeito de mudanças.

Pesquisas que antes procuravam pela descrição cultural, hoje, se preocupam com a realidade de referenciais afetivos que cada um desses sujeitos desenvolveu ao longo de suas vidas a partir da convivência com o lugar e com o outro. Referenciais carregados de sensações que trouxeram a segurança e a proteção (MELLO,1990). A sensação de lugar que tanto transmite boas lembranças quanto a sensação de lar (TUAN, 1975; BUTTIMER, 1985a).

As pesquisas procuram conhecer e reconhecer os sentidos que ligam o ser ao lugar. De acordo com Buttimer (1985b, p. 228), "lugar é o somatório das dimensões simbólicas, emocionais, culturais, políticas e biológicas". Uma simpatia que cada sujeito desenvolve com o lugar de acordo com seus próprios interesses sobre esse determinado lugar, ou seja, essa relação de afetividade que os indivíduos desenvolvem com o lugar só ocorre em virtude de estes se voltarem para ele munidos de interesses predeterminados, ou melhor, dotados de uma intencionalidade.

Através deste estudo, se reconhece que a pesquisa contemporânea procura pelo homem que dá identidade a esse lugar e aos significados construídos por ele, com a compreensão de que os lugares só adquirem identidade e significado através da intenção humana e da relação existente entre aquelas intenções e os atributos objetivos do lugar, ou seja, o cenário físico e as atividades ali desenvolvidas (RELPH, 1979). 
A partir desse novo olhar sobre os ribeirinhos amazônicos, a pesquisa já reconhece que essas comunidades atribuem valores e renovam suas representações simbólicas, agregam e codificam seus conhecimentos acumulados historicamente e os transmitem às novas gerações que fazem os mesmos processos de reinterpretação (SILVA, 2007). Em tal assertiva, os estudos de Wagley são importantes, como referência, para se pensar o espaço amazônico dotados de contradições que refletem um passado marcado pelas suas contradições e intencionalidades espaciais.

A pesquisa do ribeirinho amazônico passa, também, a reconhecer a paisagem como mediação entre o mundo das coisas e aquele da subjetividade humana, uma noção que surge ligada à percepção do espaço em cada homem/mulher amazônico. Acompanhando o pensamento de Cosgrove (1998, p.98) "A paisagem, de fato, é uma maneira de ver, uma maneira de compor e harmonizar o mundo externo em uma cena, em uma unidade visual".

Ao observar a individualidade de cada ser em sua pesquisa na Amazônia, este pesquisador contemporâneo observa também a apropriação concreta ou abstrata desse espaço por cada um desses seres, ou seja, como cada homem/mulher elabora a territorialização desse espaço (RAFFESTIN, 1993).

\section{CONCLUSÃO}

Neste estudo observou-se que os primeiros olhares através da pesquisa científica ao homem/mulher ribeirinho amazônico se deram através da antropologia. Estudos que nem sempre resultavam a favor dessas comunidades. Ressaltando nestes primeiros trabalhos o que a teoria tão bem explica: que o conceito de sentido está relacionado à noção de ponto de vista e com a possibilidade ou não de uma pessoa interpretar contextos e cenários.

Neste sentido, ao analisarmos as obras de Wagley, temos o entendimento que as mesmas são importantes clássicos que possibilitam refletir como a sociedade moderna pensa e age sobre as populações consideradas simples, sendo que estas possuem conhecimentos e valores distintos dos nossos e que podem oportunizar outras considerações e saberes que estão apartados da ciência - por vaidade e/ou 
desconhecimento desta - e da realidade colocada à nossa frente. Não podemos compreender o ser humano como dissociado da cultura e do seu meio, isso porque se trata de conhecimentos outros, com outros códigos e representações que possibilitam o entendimento da alteridade.

Pesquisas que anteriormente pretendiam falar do homem, seus conhecimentos e seus modos de vida, conformavam-se a visão do pesquisador e proviam resultados com pontos de vista equivocados a respeito do ribeirinho e sua cultura, muitas vezes, construídos e divulgados ao mundo sob sentidos imperialistas e colonizadores. No entanto, tais resultados começaram a mudar a partir da retomada linguística na Geografia e, principalmente, a partir dos estudos da Geografia Cultural.

Através da Geografia Cultural e de todas as ferramentas que essa ciência disponibiliza ao pesquisador, com as várias possibilidades da sua utilização à interdisciplinaridade, a pesquisa passou a buscar pelo conhecimento das percepções e representações dessas populações, com a compreensão de que estudos de lugares diferentes envolvem culturas diferentes, pontos de vista diferentes, de diferentes grupos sociais que produzem e reproduzem espaço e que por isso merecem ser investigados pelos geógrafos, não apenas sob o viés ecológico, mas como unidade cultural (CLAVAL, 2009).

Finalmente, essa busca por percepções (funções psicológicas que capacitam o individuo a converter os estímulos sensoriais em experiências, organizadas e coerentes) e representações (processos que permitem a evocação de objetos, paisagens e pessoas, independentemente da percepção atual deles) em populações ribeirinhas, propiciadas pela pesquisa qualitativa, pelo envolvimento cultural, com a elaboração e interpretação de mapas mentais, é que garante a construção de sentidos ao pesquisador. Serão esses sentidos que conduzirão sua pesquisa à compreensão de cada comunidade ribeirinha a ser observada. Uma compreensão não errônea das etnodiversidades a serem analisadas. Um trabalho que reflita e contemple as expectativas da sociedade ribeirinha amazônica, com a contribuição da Geografia, ao entendimento e à divulgação do seu modo de vida para futuro aproveitamento de suas tradições, valores e conhecimentos.

Neste aspecto, verifica-se que o processo pelos quais passam as populações amazônicas (caboclas, tradicionais, ribeirinhas e indígenas, entre outras), em 
múltiplas relações, o que possibilita a explicação de seu contexto socioespacial com marcas representativas no espaço e que se qualificam como construção de suas identidades culturais.

Assim, os modos de vida dessas populações constituem como culturas com suas particularidades na forma de vivenciar o espaço e de interação com o meio, caracterizando-se como identidades. O sentido posto é que nenhuma comunidade deve ser analisada pelo método comparativo, pois nelas ocorre interdependência, mas possuem características e valores próprios. O espaço do homem e mulher amazônicos é composto por vasta heterogeneidade cultural (casamentos, representações, mediações simbológicas e mitológicas, ritualidades, espiritualidades, padrões alimentares, entre outros, que se estabelecem como culturas do lugar).

E por fim, como reflexão sobre o ser amazônico tradicional, colocamos a observação de Silva; Almeida Silva \& Castro (2012, p.127):

\begin{abstract}
Diante desse quadro, os indígenas, populações "tradicionais" e "caboclas" são colocadas na linha de frente desse processo e são entendidas pela lógica econômica da sociedade abrangente como empecilho ao avanço do modelo de desenvolvimento, ou seja, porque simbolizam o atraso. Desse modo, para essas populações forçadamente "inseridas" neste modelo, suas representações e concepções de relações internas adquirem novas ressignificações, evidenciadas por novos signos e códigos que transformam profundamente suas representações sócio-espaciais e "passam" a auferir realidades estranhas ao modo de vida que até foram suficientes em sua convivência no espaço. Logo, as relações sociais, espacialidade/territorialidade antes construídas e suficientes à vida, sofrem novas intencionalidades de representação, são modificadas ou destruídas sem se conhecer a qualidade de sua eficácia e relação com o ambiente amazônico.
\end{abstract}

Provavelmente, essa estranheza de compreender o mundo tenha suscitado a Wagley e outros estudiosos a caracterizar o homem e mulher amazônicos como subdesenvolvido e atrasado naquele período. O discurso, no entanto, mantém-se inalterado por parte de setores da sociedade que veem essas populações como obstáculos aos seus projetos econômicos e que, pacificamente ou não, submetem tais comunidades à lógica do seu pensar. 


\section{REFERÊNCIAS}

ALMEIDA SILVA, Adnilson de Territorialidades e identidade dos coletivos Kawahib da Terra Indígena Uru-Eu-Wau-Wau em Rondônia: "Orevaki Are" (reencontro) dos "marcadores territoriais". Doutorado em Geografia. Curitiba: DG/PPGG/SCT/UFPR, 2010. 301p.

BUTTIMER, A. Aprendendo o dinamismo do mundo vivido. In: CHRISTOFOLETTI, A.C. (org.). Perspectivas da Geografia. São Paulo: Difel, 1985a. p.165-193.

Hogar, Campo de Movimiento y sentido del Lugar. In: RAMÓN, M.D.G. (org.). Teoria y Método en la Geografia Anglosajona. Barcelona: Ariel, p.227-241. 1985b.

CASSIRER, E. Antropología Filosófica: Introdução a uma filosofia de la cultura. $5^{\text {a }}$ ed. México: Fondo de Cultura Económica, 1968 [1944].

CLAVAL, P. Globalização, migrações, inclusão e exclusão: algumas reflexões. In: ALMEIDA, M. G \& CRUZ, B. N. Território e Cultura: inclusão e exclusão nas dinâmicas socioespaciais. Goiânia: UFG, 2009. p.10-25.

Geografia Cultural. Tradução de Luíz Fugazzola Pimenta. Florianópolis: Ed. da UFSC, 2007.

A Geografia cultural: o estado de arte. In: ROSENDAHL, Z. \& CORREAA, R. L. (Org.). Manifestações da cultura no espaço. Rio de Janeiro: EdUERJ, 1999. p.59-97.

COSGROVE, D. A geografia está em toda parte: cultura e simbolismo nas paisagens humanas. In: CORRÊA, R. L. \& ROSENDAHL, Z. (Orgs.). Paisagem, tempo e cultura. Rio de Janeiro: Editora da UERJ, 1998. p.92-122.

FURTADO, L. G. Pescadores do Rio Amazonas: um estudo antropológico da pesca ribeirinha numa área amazônica. Belém: MPEG, 1993. In: SHERER, E. \& OLIVEIRA, J. A. de. Amazônia: Políticas Públicas e Diversidade Cultural. Rio de Janeiro: Garamond. 2006.

GALVÃO, E. Panema: uma crença do caboclo amazônico. Revista do Museu Paulista, São Paulo, n.․ 5. 1951. p.221-225.

HARRIS, M. What it means to be caboclo: Some critical notes on the construction of Amazonian caboclo socity as an anthropological object. Critique of Antropology, 18:83 - 95, 1998. In: SHERER, E. \& OLIVEIRA, J. A. de. Amazônia: Políticas Públicas e Diversidade Cultural. Rio de Janeiro: Garamond, 2006.

KOZEL, S. As linguagens do cotidiano como Representações do Espaço: Uma Proposta Metodológica Possível. 2009. http://egal2009.easyplanners.info/area02/2088_KOZEL_Salete.pdf . Acesso em: 02/11/2012.

Mapas mentais - uma forma de linguagem: perspectivas metodológicas. In: KOZEL, S.; SILVA, J.C. \& GIL FILHO, S.F. (orgs.). Da Percepção e cognição à representação: Reconstruções teóricas da Geografia Cultural e Humanista. São Paulo: Terceira Margem, 2007. p.114-138.

MELLO, J. B. F. Geografia Humanística: a perspectiva da experiência vivida e uma crítica radical ao positivismo. Revista Brasileira de Geografia, 52 (4): 91-115. 1990. 
MORAN, E. The Adaptative System of the A man Caboclo. In: WAGLEY, C. Man in the Amazon. Ed. University of Florida Press, Gainsme, 1974.

NUGENT, S. Utopias e distopias na natureza social amazônica. In: ADAMS, C.; MURRIETA, R. \& NEVES, W.(orgs.). Sociedades caboclas amazônicas: modernidade e invisibilidade. São Paulo, Annablume, 2006. p. 33-44.

RAFFESTIN, C. Por uma geografia do poder. São Paulo: Ática, 1993.

RELPH, E. C. As Bases Fenomenológicas da Geografia. Geografia, 4 (7): 1-25. 1979.

SAHR, W. G. J. D. Linguagem, imagem e o performativo: Um tour d'horizon na Nova Geografia Cultural. Palestra proferida no I Colóquio Nacional do NEER. Curitiba, 2005. Disponível em: HTTP://www.invencionweb.com.br/neer/mesas. Acesso em 02/11/2012.

SILVA, J.C. O Mito e As Crenças como constituintes do Espaço Ribeirinho na Formação do Modo de Vida Amazônico. In: KOZEL, S.; SILVA, J. C.\& GIL FILHO, S.F. (Orgs.). Da Percepção e Cognição à Representação: Reconstruções Teóricas da Geografia Cultural e Humanista. São Paulo: Terceira Margem, 2007. p.207-222.

; ALMEIDA SILVA, Adnilson de. \& CASTRO, S. Novas espacialidades e organizações na vivência do ribeirinho na Amazônia. Fortaleza: Mercator (Online), v. 11, p. 121-130, 2012.

SOJA, E. Geografias pós-modernas: a reafirmação do espaço na teoria social crítica. Tradução de Vera Ribeiro. Rio de Janeiro: Jorge Zahar Editor, 1993.

SOUZA, M. História da Amazônia. Manaus: Valer, 2009.

TRINDADE JÚNIOR, S.C. \& TAVARES, M.G. (orgs.). Cidades ribeirinhas na Amazônia: mudanças e permanências. Belém: EDUFPA, 2008.

TUAN, Y. Topofilia - Um estudo de percepção, atitudes e valores do meio ambiente. (Tradução de Lívia de Oliveira). São Paulo: DIFEL, 1980.

$\overline{165.1975 .}$

Place: an experiential perspective. Geographical Review, 65 (2): 151-

WAGLEY, C. Amazon Town: A Study of Man in the Tropics. New York. 1976.

Recebido em 25.01.13. Aceito em 03.12.13. 